\title{
Locally Advanced Digestive System Carcinoma
}

National Cancer Institute

\section{Source}

National Cancer Institute. Locally Advanced Digestive System Carcinoma. NCI Thesaurus.

Code C153358.

Digestive system carcinoma that has spread to nearby tissues or lymph nodes. 